\title{
The Calibration of a Roundness Standard
}

Charles P. Reeve

National Engineering Laboratory National Bureau of Standards

Washington, D.C. 20234

June 1979

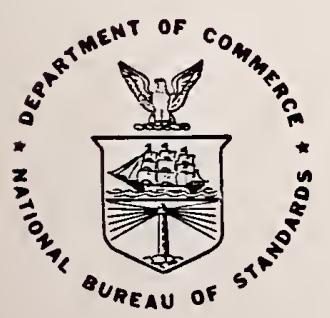

S. DEPARTMENT OF COMMERCE TIONAL BUREAU OF STANDARDS 

NBSIR 79-1758

THE CALIBRATION OF A ROUNDNESS STANDARD

Charles P. Reeve

National Engineering Laboratory

National Bureau of Standards

Washington, D.C. 20234

June 1979

U.S. DEPARTMENT OF COMMERCE, Juanita M. Kreps, Secretary Jordan J. Baruch, Assistant Secretary for Science and Technology NATIONAL BUREAU OF STANDARDS, Ernest Ambler, Director 



\section{Contents}

1. Introduction $\ldots \ldots \ldots \ldots \ldots \ldots \ldots \ldots \ldots \ldots \ldots \ldots \ldots \ldots \ldots \ldots \ldots$

2. Preliminaries ................................ 1

2.1. Roundness Measuring Instruments ................ 1

2.2. The Polar Graph ......................... 2

2.3. Methods of Determining Roundness ................ 2

3. Procedure for Taking Data ....................... 5

4. Mathematical Model ............................ 8

4.1. Parameters ............................. 8

4.2. Measurement Equations ..................... 9

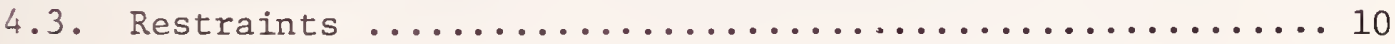

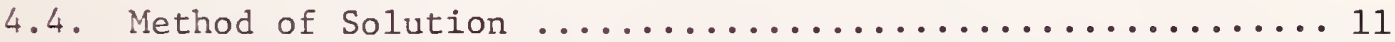

4.5. Simplified Expression of Results ................ 12

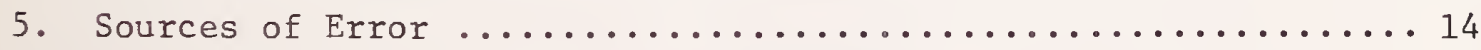

6. Graphical Display of Roundness Profile ................ 14

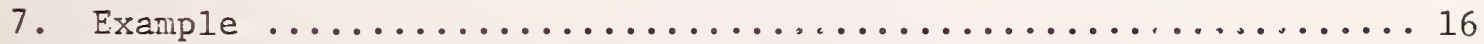

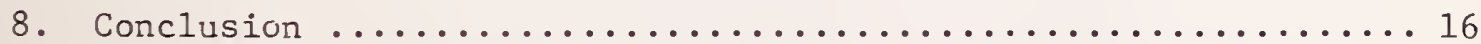

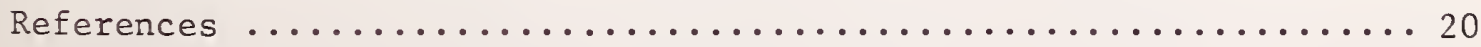



The Calibration of a Roundness Standard

by

Charles P. Reeve

\section{Introduction}

The Dimensional Metrology Group of the National Bureau of Standards has been making roundness measurements for many years. In some of the measurements a high level of precision is not needed. This usually occurs for objects such as cylinders, spheres, and ring gages where roundness is not the parameter of primary importance. In these cases it is routine to make a single trace with a roundness measuring instrument whose output is a polar graph. Much literature has been devoted to the interpretation of data taken in this form.

When calibrating objects which are to be used solely as roundness standards, such as hemispheres, a higher level of precision is called for. During the last decade a measurement algorithm has been used at NBS which is unlike any thus far found in the literature. It involves making several traces of the roundness standard (also referred to as the "workpiece") where the standard is rotated between traces. A least squares analysis is performed on the resulting measurements enabling the noncircularity in the spindle to be separated from the profile of the standard.

The primary purpose of this paper is to present a detailed description of the mathematical model for this particular measurement process. Certain related topics are discussed briefly. A method of graphically displaying the roundness profile is described and an example is given. Topics not discussed because of their availability in the 1iterature are effects of stylus type, alignment of stylus, alignnent of workpiece, and effects of imperfect centering.

\section{Preliminaries}

\subsection{Roundness Measuring Instruments}

There are two basic types of high precision roundness measuring instruments. One type has a high precision spindle which carries a sensitive indicator (stylus) around the circumference of the workpiece which is held stationary. The other type has a high precision turntable which rotates the workpiece against a stylus which is held stationary. NBS currently has both types of instruments. 


\subsection{The Polar Graph}

The output in most roundness calibrations is a polar graph. The roundness profile of the workpiece is transferred to the graph as the surface of the workpiece deflects the stylus. The continuous trace represents the radial deviations of the workpiece from the center of rotation of the spindle. Included in the trace are the deviations from circularity of the path of the spindle. The magnification factor exaggerates the profile in the radial direction, but the angular positions on the graph retain the same relationship as on the workpiece itself.

In some cases the output of a roundness trace consists not of a polar graph but of a set of $n$ numbers which represent the radial deviations of the workpiece at $n$ equally spaced points around the circumference. This is equivalent to a polar graph except that the trace consists of a discrete number of points instead of a continuous curve.

Whether discrete or continuous, the trace may be interpreted in several ways as described in the following section.

\subsection{Methods of Determining Roundness}

There are several ways to assign numerical "roundness" values to the workpiece from its polar graph. One way is to draw either the minimum circumscribing circle or the maximum inscribed circle and state the maximum departure from one or the other. Another way is to draw the pair of concentric circles which enclose the graph and have the minimum radial separation. This separation is then a measure of the "out-ofroundness". Examples of the above are illustrated in some of the references $[2,5,8,10]$.*

A slightly more sophisticated approach is to fit a "least squares circle" (LSC) to the graph. The LSC is fit through an integral number of equally spaced points on the curve rather than through the entire curve. The maximum deviation from the LSC is then another measure of the "out-of-roundness" of the workpiece.

The following derivation of the equations for the LSC is a summary of the more rigorous derivations given in several of the references $[2,5,7,10,11]$.

Consider a polar graph given in a rectangular coordinate system as shown in figure 2.1. Let point 0 be the center of rotation of the spindle and $y_{i}$ be the distance from 0 to point $P$ on the curve at the angular position $\theta_{i}$. Let point $(a, b)$ be the center of the LSC and $R$ be the radius of the LSC. Let $c^{2}=a^{2}+b^{2}$ and $\tan \alpha=b / a$. Then the triangle between points $0, P$, and $(a, b)$ has the relationship

$$
y_{i}=\left[\left(R+\Delta_{i}\right)^{2}-c^{2} \sin ^{2}\left(\theta_{i}-\alpha\right)\right]^{1 / 2}+c \cos \left(\theta_{i}-\alpha\right)
$$

*Figures in brackets indicate literature references listed at the end of this paper. 


\section{DETERMINATION OF LEAST SQUARES CIRCLE}

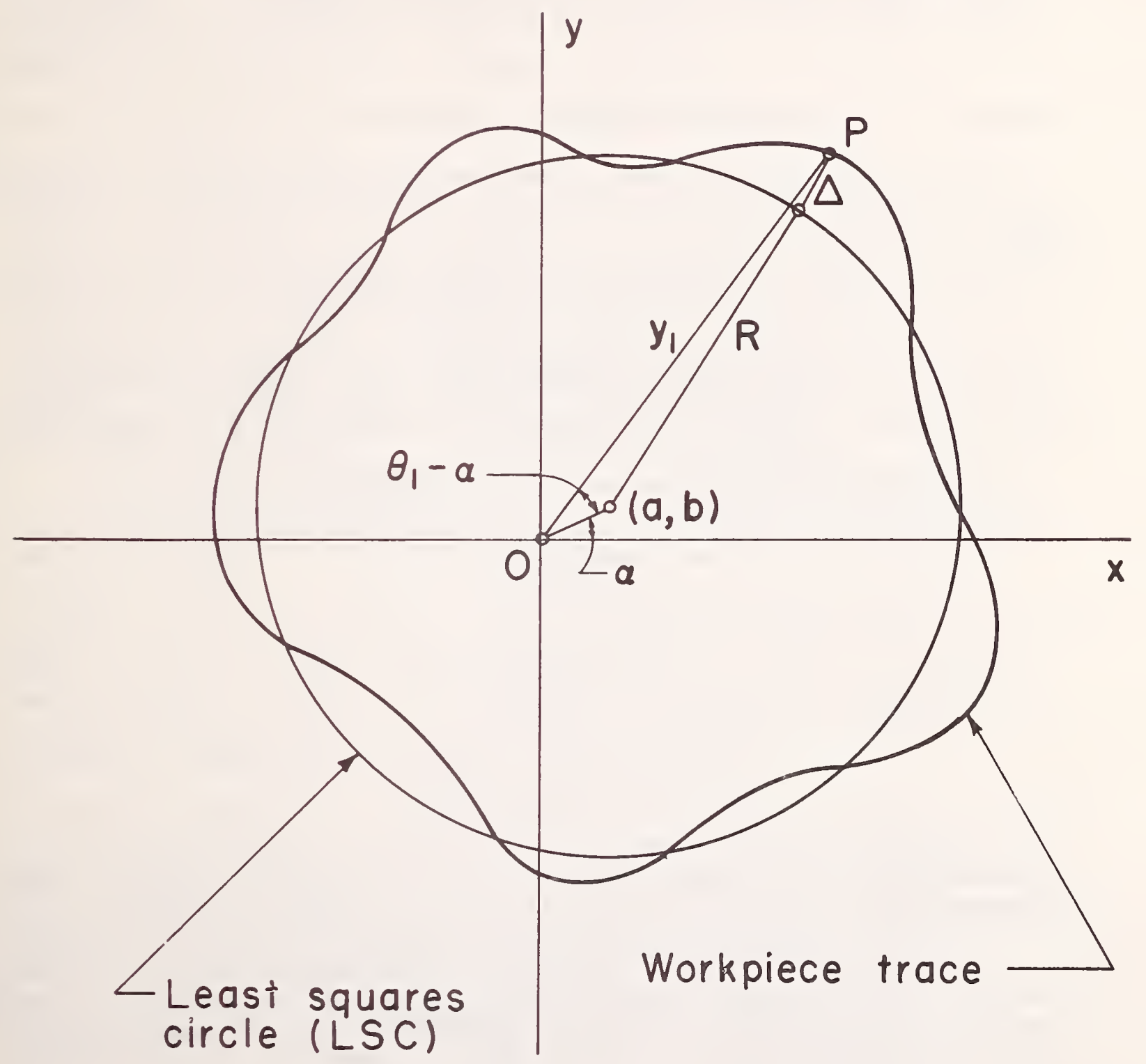

Figure 2.1 
where $\Delta_{1}$ is the deviation of point $P$ from the LSC.

Since $c$ is many orders of magnitude less than $R$ (in a well centered trace), the term $c^{2} \sin ^{2}\left(\theta_{i}-\alpha\right)$ can be neglected, thus

$$
y_{i}=R+c \cos \left(\theta_{i}-\alpha\right)+\Delta_{i} \text {. }
$$

Since $a=c \cos \alpha$ and $b=c \sin \alpha$ this expression can be expanded to give

$$
y_{i}=R+c \cos \theta_{i} \cos \alpha+c \sin \theta_{i} \sin \alpha+\Delta_{i},
$$

or

$$
y_{i} R+a \cos \theta_{i}+b \sin \theta_{i}+\Delta_{i}
$$

Let $\left\{\theta_{1}, i=1, n\right\}$ be $n$ equally spaced angles. Then the sum of squares of the deviations, $\sum_{i=1}^{n} \Delta_{i}^{2}$, is minimized by the usual method of least squares to give the following estimates for the LSC parameters:

$$
\begin{aligned}
& \hat{\mathrm{R}}=\frac{1}{\mathrm{n}} \sum_{i=1}^{\mathrm{n}} \mathrm{y}_{i} \\
& \hat{\mathrm{a}}=\frac{2}{\mathrm{n}} \sum_{i=1}^{\mathrm{n}} \mathrm{y}_{i} \cos \theta_{i}, \text { and } \\
& \hat{\mathrm{b}}=\frac{2}{\mathrm{n}} \sum_{i=1}^{\mathrm{n}} \mathrm{y}_{i} \sin \theta_{i} .
\end{aligned}
$$

The deviations $\Delta_{i}$ are given by $\Delta_{i}=y_{i}-\hat{R}-\hat{a} \cos \theta_{i}-\hat{b} \sin \theta_{i}$ where $i=1, n$.

When roundness values are assigned from a single graph, as in the above sabes, the graph contains both the workpiece profile and tile spindle profile. In a precision instrument the spindle error is usually small and within known limits and can be ignored except when the most precise measurements are needed.

There are currently two methods available for removing spindle error at the cost of making multiple traces. One method requiring two traces is given by Donaldson [4] for use on a turntable-type instrument. Between traces the workpiece and stylus positions are rotated $180^{\circ}$ while the shaft and housing positions remain the same. If both graphs are recorded on the same chart the true workpiece profile is obtained by drawing a third graph halfway between the two. Though well suited for a turntabletype instrument, this method is not easily adapted to a spindle-type instrument. 
The other method of removing spindle error is the main topic of this paper. It requires several polar graphs and works equally well on either type of instrument. A detailed discussion of this method as applied to a spindle-type instrument is given in the following sections.

\section{Procedure for Taking Data}

The workpiece should be centered as well as possible under the spindle. The mark on the workpiece which donotes the zero angular position is aligned with the zero position of the spindle as shown in figure 3.1. A trace is made with the workpiece in this position. The workpiece is then rotated clockwise by $360 / \mathrm{n}$ degrees as shown in figure 3.2 and another trace is made. This process is continued until $\mathrm{n}$ traces have been made. The value of $\mathrm{n}$ is arbitrary but is usually at least 4 . Note in the above figures that the zero spindle position is shown pointing "south". This convention was arbitrarily chosen for the current measuring instrument.

It is important to record the angle $\delta$ between the lever arm of the stylus and the tangent to the workpiece at the point of contact. This angle can usually be set to $0^{\circ}$ for a sphere, hemisphere, or cylinder as shown in figures $3.3,3.4$, and 3.5 respectively. If an obstruction exists, as shown in figure 3.6 , then the angle must necessarily be greater than $0^{\circ}$. The correction for $\delta$ assures that the profile of the workpiece will be measured normal to the point of contact. A sphere is normally measured about its equator. A hemisphere is measured as nearly to the base as possible without the stylus being obstructed. A cylinder is measured at some specified distance above its base.

If the output of the instrument is a polar graph for each trace of the workpiece, then the observer should measure the radial distance (in polar graph units) from the center of each graph to the curve at each of the $n$ angular positions and record the values on the graphs at the proper places. The graphs should be numbered from 1 to $\mathrm{n}$ and the scale factor (K) of the instrument should be noted on at least one of them.

\section{Mathematica1 Mode1}

\subsection{Parameters}

Let the $n$ angular positions on the circumference of the workpiece be numbered counterclockwise from 1 to $n$ beginning with the $0^{\circ}$ position. Let the angular positions of the spindle be similarly numbered without regard to the direction in which the spindle rotates. The $i^{\text {th }}$ angular position is then denoted by

$$
\theta_{i}=\frac{360(i-1)}{n} \text { degrees }
$$



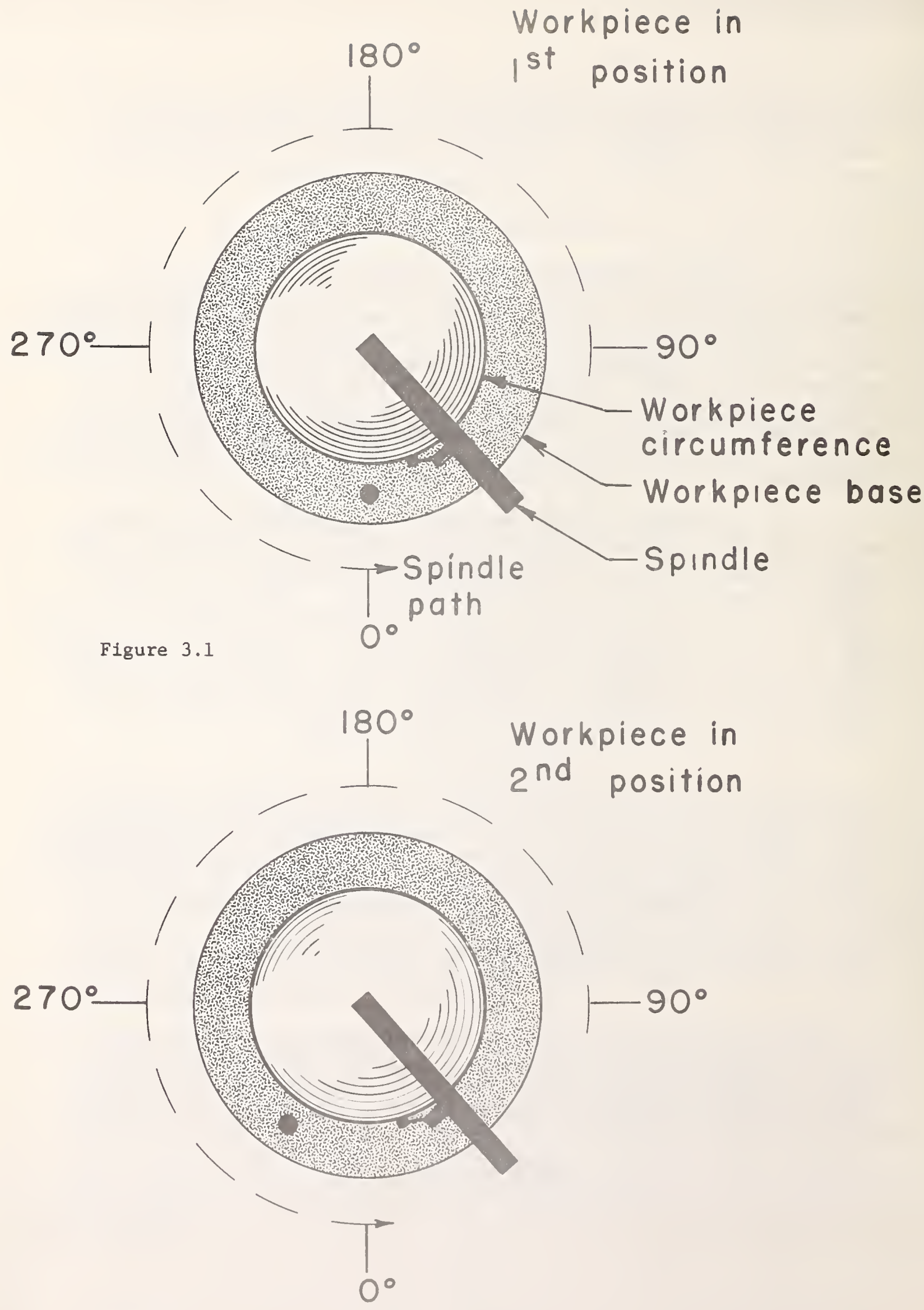

Figure 3.2 
Sphere

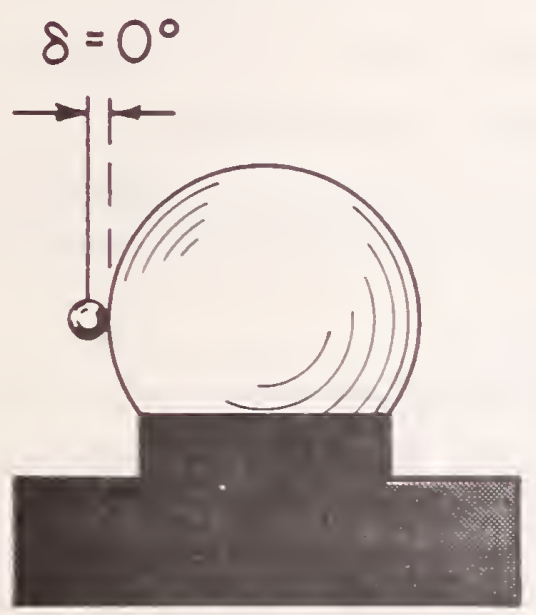

Figure 3.3

Cylinder

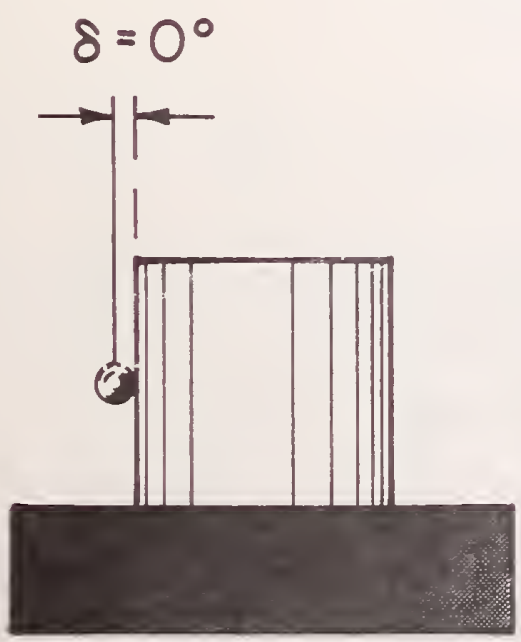

Figure 3.5
Hemisphere

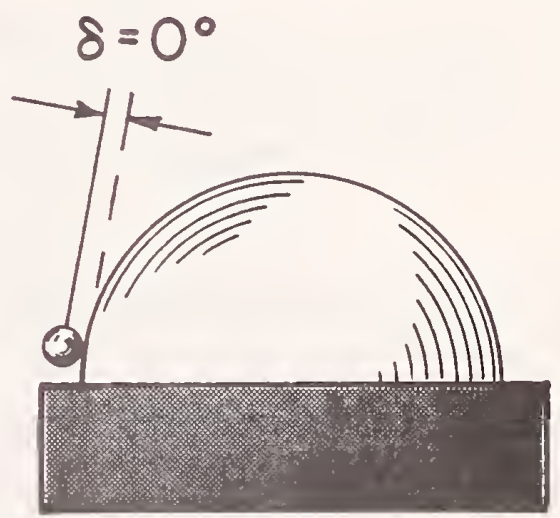

Figure 3.4

Cylinder (with cap)

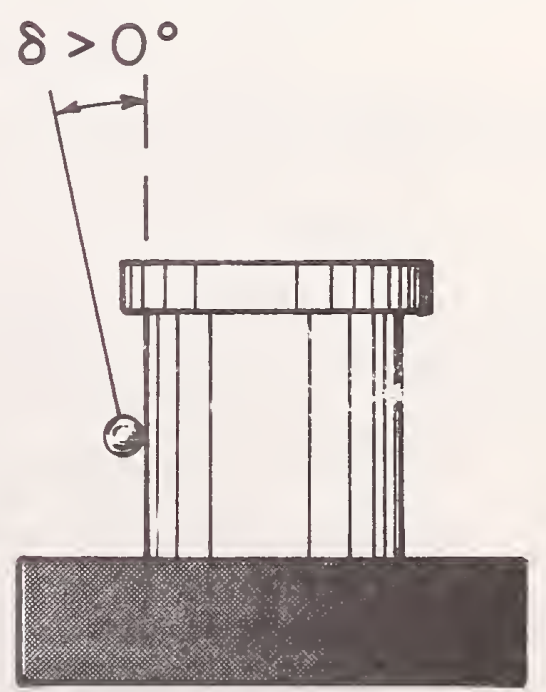

Figure 3.6 
where $i=1, n$. Let the deviations from the LSC of the workpiece at the $\theta_{i}$ position be given by $\alpha_{i}$, and let the deviation of the spindle from its LSC at the $\theta_{i}$ position be given by $\beta_{i}$. For the $j^{\text {th }}$ graph let the three parameters which define the LSC on the graph be given by $R_{j}, a_{j}$, and $b_{j}$ (see equation 2-4). In an idealized measurement system these parameters would be constant for all j. In reality, though, each rotation of the workpiece causes it to shift a small amount vertically and horizontally. To account for this shifting, separate parameters are needed for each trace.

Let $y_{i j}$ be the observed distance (in polar graph units) from the center of the $j^{\text {th }}$ graph to the point on the curve which corresponds to the $\theta_{i}$ position of the spindle. Let $K$ be the magnification factor of the measuring instrument given in (microinches/polar graph unit)*, and let $z_{i j}$ be given by

$$
z_{i j}=(K \cos \delta) y_{i j}
$$
for $i=1, n$ and $j=1, n$. The $z_{i j}$ 's are then the observations to be used in
the mathematical model.

\subsection{Measurement Equations}

The measurement equations take the form

$$
z_{i j}=\alpha_{i+j-1}-\beta_{i}+R_{j}+a_{j} \cos \theta_{i}+b_{j} \sin \theta_{i}+\varepsilon_{i j}
$$

where the $\varepsilon_{i j}$ are independent error values from a distribution with mean zero and variance $\sigma^{2}$. (The subscrjpt of $\alpha$ is reduced modulo $\mathrm{n}_{\text {.) }}$ Let

$$
\begin{aligned}
& z=\left(z_{11} \ldots z_{n 1} z_{12} \ldots z_{n 2} \cdots z_{1 n} \ldots z_{n n}\right)^{\prime}, \\
& \alpha=\left(\alpha_{1} \ldots \alpha_{n}\right)^{\prime}, \\
& \beta=\left(\beta_{1} \ldots \beta_{n}\right)^{\prime}, \\
& \phi=\left(R_{1} a_{1} b_{1} \ldots R_{n} a_{n} b_{n}\right)^{\prime}, \\
& \varepsilon=\left(\varepsilon_{11} \ldots \varepsilon_{n 1} \varepsilon_{12} \cdots \varepsilon_{n 2} \cdots \varepsilon_{1 n} \cdots \varepsilon_{n n}\right)^{\prime}, \text { and }
\end{aligned}
$$

*Customary U.S. units are used in this report rather than the recognized metric (SI) units. The well established ongoing calibration procedures described here employ customary units exclusively. The conversion to SI units will be made at a future time. 


$$
X=\left[\begin{array}{ccccc}
\mathrm{P}^{0} & -\mathrm{I} & \mathrm{A} & 0 & 0 \\
\mathrm{P}^{1} & -\mathrm{I} & 0 & \mathrm{~A} & 0 \\
\vdots & & & \ddots & \\
\mathrm{P}^{\mathrm{n}-1}-\mathrm{I} & 0 & 0 & \mathrm{~A}
\end{array}\right]
$$

where ' denotes matrix or vector transposition, and $\mathrm{P}^{1}$ is the $\mathrm{n} \times \mathrm{n}$ permutation matrix given by

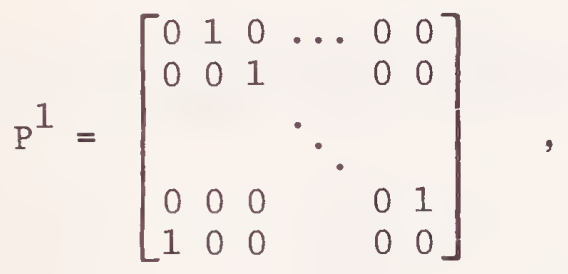

$I$ is the nxn identity matrix, and $A$ is the $n x 3$ matrix given by

$$
A=\left[\begin{array}{ccc}
1 & \cos ^{\theta} 1 & \sin \theta_{1} \\
1 & \cos \theta_{2} & \sin \theta_{2} \\
& \vdots & \\
1 & \cos \theta_{n} & \sin \theta_{n}
\end{array}\right] \text {. }
$$

(Note that $\mathrm{P}^{\mathrm{O}}=\mathrm{P}^{\mathrm{n}}=\mathrm{I}_{\text {.) }}$ The measurement equations can then be written in the matrix form

$$
z=X\left[\begin{array}{l}
\alpha \\
\beta \\
\phi
\end{array}\right]+\varepsilon
$$

\subsection{Restraints}

The $\mathrm{n}^{2}$ by $5 \mathrm{n}$ system given above has no unique least squares solution because the restraints which were arbitrarily set on $\alpha$ and $\beta$ (that they be deviations from least squares circles) have not yet been included in the model. These are included by adding the six equations

$$
\sum_{i=1}^{n} \alpha_{i}=\sum_{i=1}^{n} \alpha_{i} \cos \theta_{i}=\sum_{i=1}^{n} \alpha_{i} \sin \theta_{i}=0
$$

and 


$$
\sum_{i=1}^{n} \beta_{i}=\sum_{i=1}^{n} B_{i} \cos \theta_{i}=\sum_{i=1}^{n} \beta_{i} \sin \theta_{i}=0
$$

to the model. In matrix notation the restraints take the form

$$
A^{\prime} \alpha=A^{\prime} B=0
$$

where $A$ is defined as in equation $4-4$.

\subsection{Method of Solution}

The model can now be solved by the method of restrained least squares [3]. The least squares estimation takes the form

$$
E(z)=x\left[\begin{array}{l}
\alpha \\
\beta \\
\phi
\end{array}\right]
$$

where

$$
\operatorname{Var}(z)=\sigma^{2} I
$$

The normal equations (incorporating the six restraints) take the form

$$
\left[\begin{array}{ccccc} 
& & & A & 0 \\
X^{\prime} X & & 0 & A \\
& & & 0 & 0 \\
A^{\prime} & 0 & 0 & 0 & 0 \\
0 & A^{\prime} & 0 & 0 & 0
\end{array}\right]\left[\begin{array}{l}
\alpha \\
\beta \\
\phi \\
\lambda
\end{array}\right]\left[\begin{array}{l}
X^{\prime} z \\
0 \\
0
\end{array}\right]
$$

where $\lambda=\left(\lambda_{1} \lambda_{2} \ldots \lambda_{6}\right)^{\prime}$ are Lagrangian multipliers entering in the minimization process. The least squares estimates of the unknowns are given. by

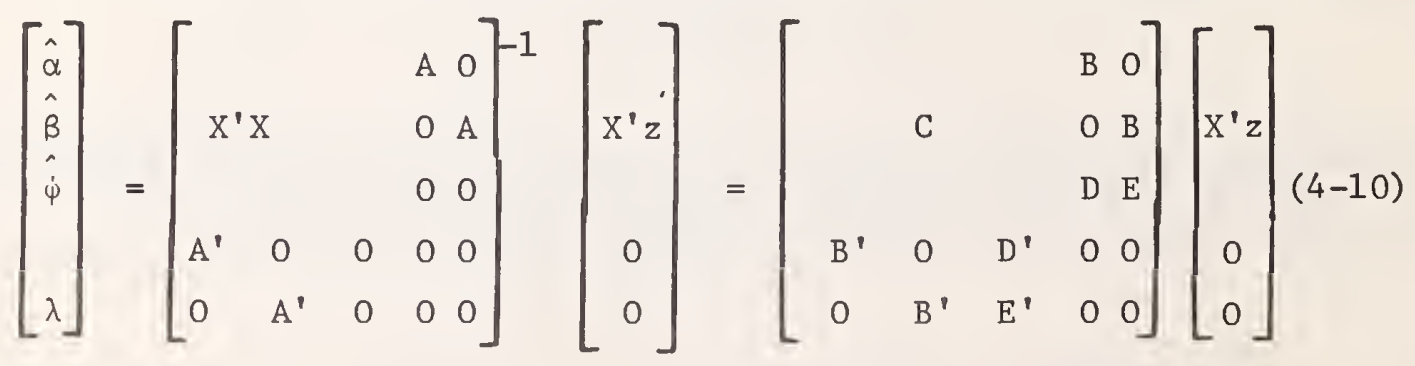

where $\mathrm{C}$ is the variance-covariance matrix of the estimates. The predicted values of the observations are given by 


$$
\hat{z}=x\left[\begin{array}{l}
\hat{\alpha} \\
\hat{\beta} \\
\hat{\phi}
\end{array}\right]
$$

and the deviations by

$$
\mathrm{d}=\mathrm{z}=\hat{\mathrm{z}}
$$

The estimate of $\sigma$ is given by

$$
s=\sqrt{d \cdot d /\left(n^{2}-5 n+6\right)} \text {. }
$$

and the standard deviation of the estimates by

$$
s_{\hat{\alpha}_{i}}=\sqrt{C_{i i}} s \text { and } s_{\hat{\beta}_{i}}=\sqrt{C_{n+i, n+i}} s
$$

\subsection{Simplified Expression of Results}

The matrix of normal equations and its inverse, both given in equation 4-10, can be written more specifically as

$$
\left[\begin{array}{ccccccc}
n I & -J & \mathrm{P}^{\mathrm{A}} \mathrm{A} & \cdots & \mathrm{P}^{1} A & A & 0 \\
-J & \mathrm{nI} & -\mathrm{A} & \cdots & -A & 0 & \mathrm{~A} \\
\mathrm{~A}^{\prime} \mathrm{P}^{1} & -\mathrm{A}^{\prime} & \mathrm{A}^{\prime} \mathrm{A} & & 0 & 0 & 0 \\
& \vdots & & \ddots & & & \\
\mathrm{A}^{\prime} \mathrm{P}^{\mathrm{n}} & -\mathrm{A}^{\prime} & 0 & & \mathrm{~A}^{\prime} \mathrm{A} & 0 & 0 \\
\mathrm{~A}^{\prime} & 0 & 0 & \cdots & 0 & 0 & 0 \\
0 & \mathrm{~A}^{\prime} & 0 & & 0 & 0 & 0
\end{array}\right]
$$

and 


$$
\left[\begin{array}{ccccccc}
\frac{1}{n}\left(I-\mathrm{AQ}_{0} \mathrm{~A}^{\prime}\right) & 0 & 0 & & 0 & \mathrm{AQ}_{0} & 0 \\
0 & \frac{1}{\mathrm{n}}\left(I-\mathrm{AQ}_{0} \mathrm{~A}^{\prime}\right) & 0 & \cdots & 0 & 0 & \mathrm{AQ}_{0} \\
0 & 0 & \mathrm{Q}_{0} & & 0 & -\mathrm{Q}_{\mathrm{n}} & \mathrm{Q}_{0} \\
& & & \ddots & & & \\
0 & 0 & 0 & & \mathrm{Q}_{0} & -\mathrm{Q}_{1} & \mathrm{Q}_{0} \\
\mathrm{Q}_{0} \mathrm{~A}^{\prime} & 0 & -\mathrm{Q}_{0} & \cdots & -\mathrm{Q}_{\mathrm{n}-1} & 0 & 0 \\
0 & \mathrm{Q}_{0} \mathrm{~A}^{\prime} & \mathrm{O}_{0} & \cdots & \mathrm{Q}_{0} & 0 & 0
\end{array}\right]
$$
where $Q_{i}=\left(A^{\prime} P^{i} A\right)^{-1}$. The expressions for the estimates can be reduced
to

$$
\begin{aligned}
& \hat{\alpha}_{i}=\sum_{j=1}^{n} \sum_{k=1}^{n} t_{k-i+j+n} z_{k j}, \\
& \hat{\beta}_{i}=-\sum_{j=1}^{n} \sum_{k=1}^{n} t_{k-i+1+n} z_{k j}, \\
& \hat{R}_{j}=\frac{1}{n} \sum_{k=1}^{n} z_{k j}, \\
& \hat{a}_{j}=\frac{2}{n} \sum_{k=1}^{n} z_{k j} \cos \theta_{k}, \text { and } \\
& \hat{b}_{j}=\frac{2}{n} \sum_{k=1}^{n} z_{k j} \sin \theta_{k}
\end{aligned}
$$

where

$$
t_{m}=\left\{\begin{array}{cl}
\frac{n-3}{n^{2}} & \text { if } m=1 \text {, and } \\
-\frac{1}{n^{2}}\left(1+2 \cos \theta_{m}\right) & \text { if } 2 \leq m \leq n .
\end{array} .\right.
$$


(The subscripts of $t$ are reduced modulo n.) The standard deviation of the profile estimates is given by

$$
s_{\hat{\alpha}_{i}}=s_{\hat{\beta}_{i}}=\frac{\sqrt{n-3}}{n} \mathrm{~s}
$$

for $i=1, n$.

\section{Sources of Error}

Some known sources of error in roundness measurement are:

(1) horizontal and vertical fluctuations of spindle path from one trace to the next,

(2) variability due to stylus type,

(3) nonuniformity of polar graphs on which traces are recorded, and

(4) variability in observer's interpolation of trace position on polar graph.

These errors are assumed to accumulate in a random fashion and thus are included in the estimate of the standard deviation.

\section{Graphical Display of Roundness Profile}

In the measurement of roundness it is particularly useful to have a graph of the measured profile. The $n$ values obtained from the previously described method of calibration can be plotted on a polar graph to give an indication of the shape of the workpiece. This graph can be enhanced by connecting the points with a smooth curve. One good method of doing this involves the use of periodic cubic spline functions. Let the set of points $\left\{\left(\theta_{i}, \hat{\alpha}_{i}\right), i=1, n+1\right\}$ represent the profile of the workpiece in rectangular coordinates where $\theta_{n+1}=\theta_{n}+\theta_{2}$ and $\hat{\alpha}_{n+1}=\hat{\alpha}_{1}$ as shown in figure 6.1. In each of the intervals $\left\{\left(\theta_{i}, \theta_{i+1}\right), i=1, n\right\}$ a cubic polynomial is fit to the points subject to the condition that the cubic between $\theta_{i-1}$ and $\theta_{i}$ must agree with the cubic between $\theta_{i}$ and $\theta_{i+1}$ at $\theta_{i}$ in their first and second derivatives. Similarly, the cubic between $\theta_{1}$ and $\theta_{2}$ must agree with the cubic between $\theta_{n}$ and $\theta_{n+1}$ at $\theta_{1}$ and $\theta_{n+1}$. The last requirement makes the spline periodic. 
RECTANGULAR GRAPH OF ROUNDNESS PROFILE

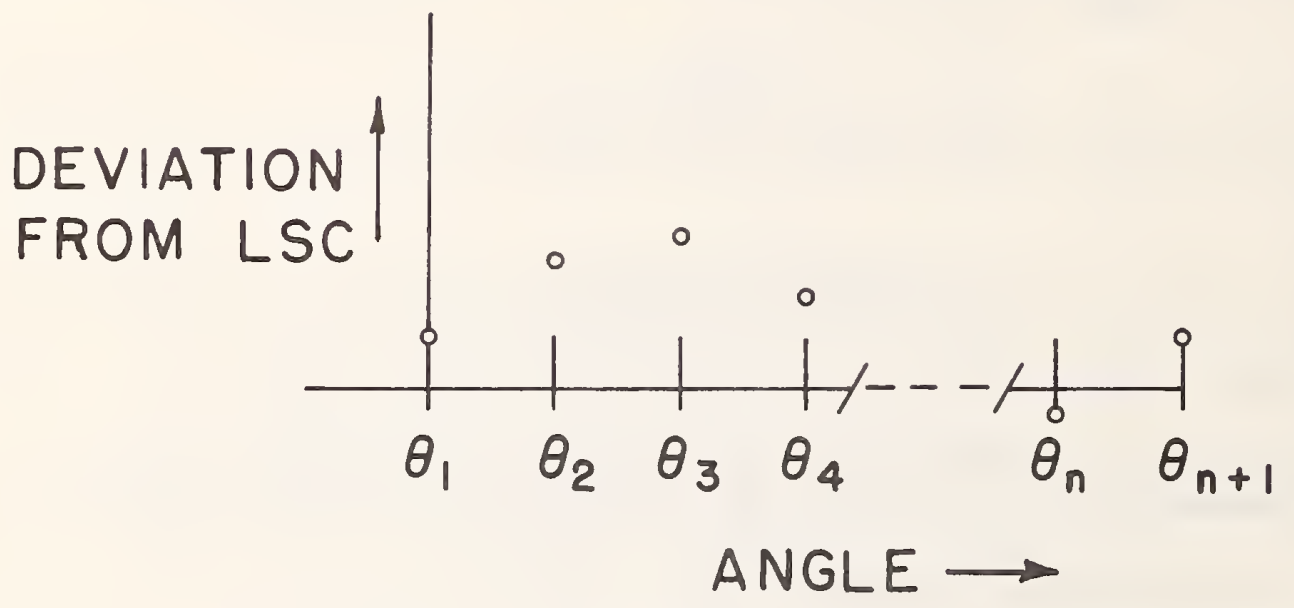

Figure 6.1

POLAR GRAPH OF ROUNDNESS PROFILE

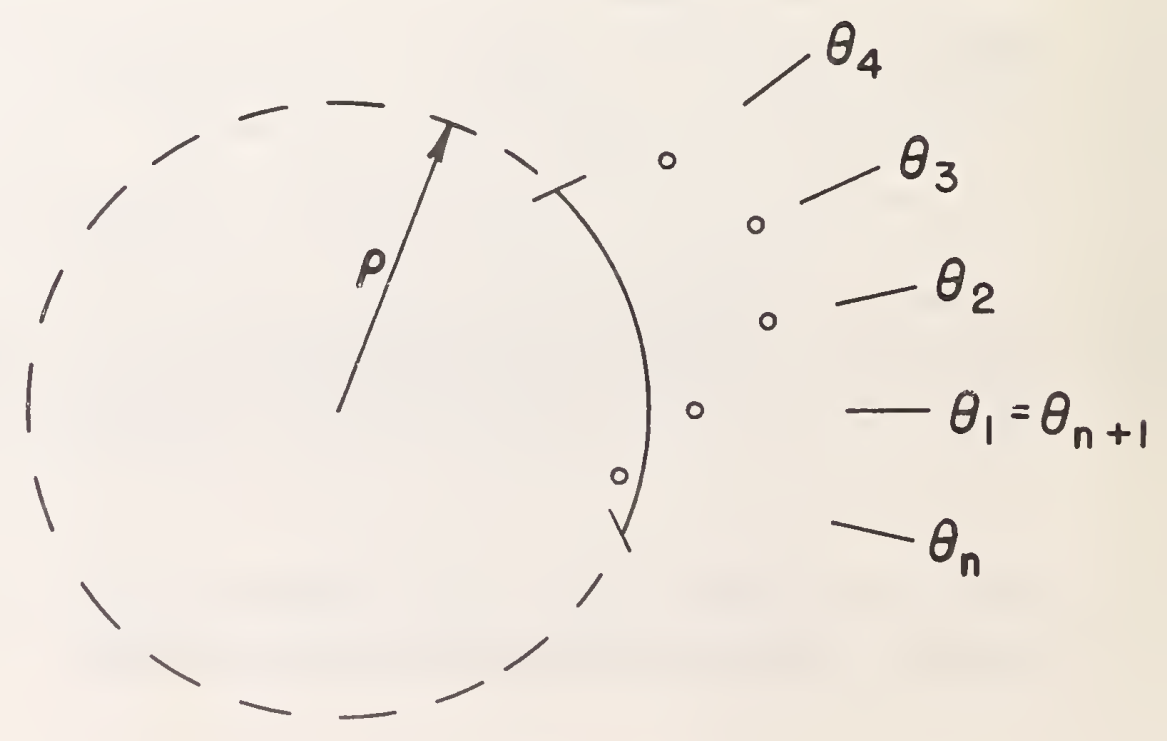

Figure 6.2 
The resulting equations form a system of $3 n$ equations in $3 n$ unknowns which is tridiagonal except for nonzero elements in the upper right and lower left hand corners of the associated matrix. In the current computer program the equations are formulated by extending the method given in UNIVAC [12] for a nonperiodic cubic spline. The resulting equations are then solved by the method given in Ahlberg [1] for a periodic spline. Once the coefficients of the $n$ cubics are obtained the interpolated value at a given $\theta_{0}$ is determined by plugging the value of $\theta_{0}$ into the appropriate cubic. The rectangular graph is then transformed to a polar graph by plotting the set of points $\left\{\left(\rho+\alpha_{i}, \theta_{i}\right), i=1, n\right\}$ where $\rho+\hat{\alpha}_{i}$ is the distance from the origin and $\theta_{i}$ is the angle (see fig. 6.2). The parameter $\rho$ is an arbitrary constant. Note that $\theta_{n+1}$ is identical to $\theta_{1}$ on the polar graph.

\section{Example}

A glass hemisphere designated 29474 was measured on a spindle-type instrument. Twelve traces were made with the hemisphere rotated $30^{\circ}$ between each trace. The radial distances $y_{j}$ (in polar graph units) were recorded at $30^{\circ}$ intervals on each trace as shown in figure 7.1. The scale factor was determined to be $\mathrm{K}=5.56 \mathrm{microinches} / \mathrm{unit}$ and $\delta$ was approximately $0^{\circ}$. The true radial distances $z_{i j}=(K \cos \delta) y_{i j}$ where $i=1, n$ and $j=1, n$ were computed. Then using equations 4-15 and 4-16 the estimates of the unknown parameters were computed as given in figure 7.2. (Note also the standard deviation values.) The profile of the hemisphere was plotted by the computer as shown in figure 7.3. The small "**" signs indicate the values of the least squares estimates $\hat{\alpha}$ for $i=1,12$ relative to the dotted circle (outward is + ). In this example interpolated values were computed at 720 equally spaced points. The values were connected by straight lines, but due to their closeness they give the appearance of a smooth continuous curve. The estimates $\hat{R}_{j}, \hat{a}_{j}$, and $\hat{b}_{j}$ are omitted because they are normally not of interest. The total uncertainty of each profile value was taken to be the three standard deviation limit for random errur.

\section{Conclusion}

The data reduction process is now fully computerized and incorporates the simplified expressions for the estimates given in equations $4-15$ and 4-16. The output includes the usual Report of Calibration plus a plot of the computed roundness profile.

The strong point of this method of roundness measurement is that it allows the spindle error to be separated from the workpiece profile while giving an estimate of the measurement precision. It should be used whenever the desired level of precision is so great that the out-of-roundness of the spindle path becomes significant. 


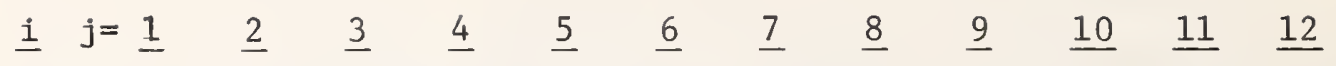

$\begin{array}{lllllllllllll}1 & 8.1 & 6.9 & 6.7 & 5.3 & 7.5 & 6.9 & 5.6 & 7.2 & 7.0 & 7.8 & 7.2 & 7.2\end{array}$

$\begin{array}{lllllllllllll}2 & 7.2 & 6.8 & 6.2 & 5.1 & 7.4 & 6.7 & 5.4 & 7.1 & 6.9 & 7.8 & 7.2 & 6.3\end{array}$

$\begin{array}{lllllllllllll}3 & 6.6 & 6.8 & 6.0 & 5.1 & 7.2 & 6.3 & 5.3 & 6.9 & 6.8 & 7.3 & 7.1 & 6.0\end{array}$

$\begin{array}{lllllllllllll}4 & 6.1 & 6.7 & 6.0 & 5.1 & 7.0 & 5.9 & 5.4 & 6.3 & 6.8 & 6.9 & 7.0 & 5.7\end{array}$

$\begin{array}{lllllllllllll}5 & 5.6 & 6.2 & 6.2 & 5.2 & 6.8 & 5.7 & 5.6 & 6.0 & 6.9 & 6.2 & 7.1 & 5.4\end{array}$

$\begin{array}{lllllllllllll}6 & 5.5 & 6.0 & 6.8 & 5.3 & 6.5 & 5.5 & 5.8 & 5.8 & 7.0 & 5.7 & 7.1 & 5.5\end{array}$

$\begin{array}{lllllllllllll}7 & 5.8 & 5.7 & 7.4 & 5.4 & 6.5 & 5.6 & 6.0 & 5.7 & 7.3 & 5.4 & 7.1 & 5.9\end{array}$

$\begin{array}{lllllllllllll}8 & 6.3 & 5.6 & 7.9 & 5.6 & 6.7 & 6.0 & 6.2 & 5.8 & 7.6 & 5.3 & 7.0 & 6.2\end{array}$

$\begin{array}{lllllllllllll}9 & 6.9 & 5.8 & 8.0 & 5.6 & 6.8 & 6.0 & 6.1 & 5.9 & 7.7 & 5.3 & 7.0 & 6.9\end{array}$

$\begin{array}{lllllllllllll}10 & 7.7 & 6.0 & 8.0 & 5.7 & 7.0 & 6.4 & 6.0 & 6.2 & 7.3 & 6.0 & 7.0 & 7.0\end{array}$

$\begin{array}{lllllllllllll}11 & 8.3 & 6.3 & 7.8 & 5.5 & 7.2 & 6.8 & 5.9 & 6.7 & 7.2 & 6.5 & 7.0 & 7.3\end{array}$

$\begin{array}{lllllllllllll}12 & 8.5 & 6.8 & 7.3 & 5.3 & 7.3 & 6.9 & 5.7 & 7.0 & 7.0 & 7.1 & 7.0 & 7.2\end{array}$

$\mathrm{K}=5.56$ microinches/polar chart unit

$\delta=0^{\circ}$

Figure 7.1

Least squares estimates of profiles

(microinches)

$\left(\hat{\alpha}_{i}\right)$

Position

$0^{\circ}$
$30^{\circ}$

$60^{\circ}$

$90^{\circ}$

$120^{\circ}$

$150^{\circ}$

$180^{\circ}$

$210^{\circ}$

$240^{\circ}$

$270^{\circ}$

$300^{\circ}$

$330^{\circ}$
Hemisphere

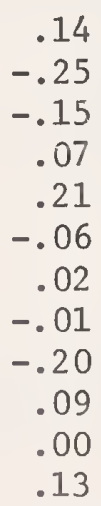

$\left(\hat{\beta}_{i}\right)$

Spindle

$-.48$

.10

.10

.04

.12

.05

$-.15$

$-.30$

.11

.26

.09

.06

Std. dev. of residuals $=.50$ microinch

Std. dev. of estimates $=.13$ microinch Uncertainty of estimates $=.38$ microinch

Figure 7.2 


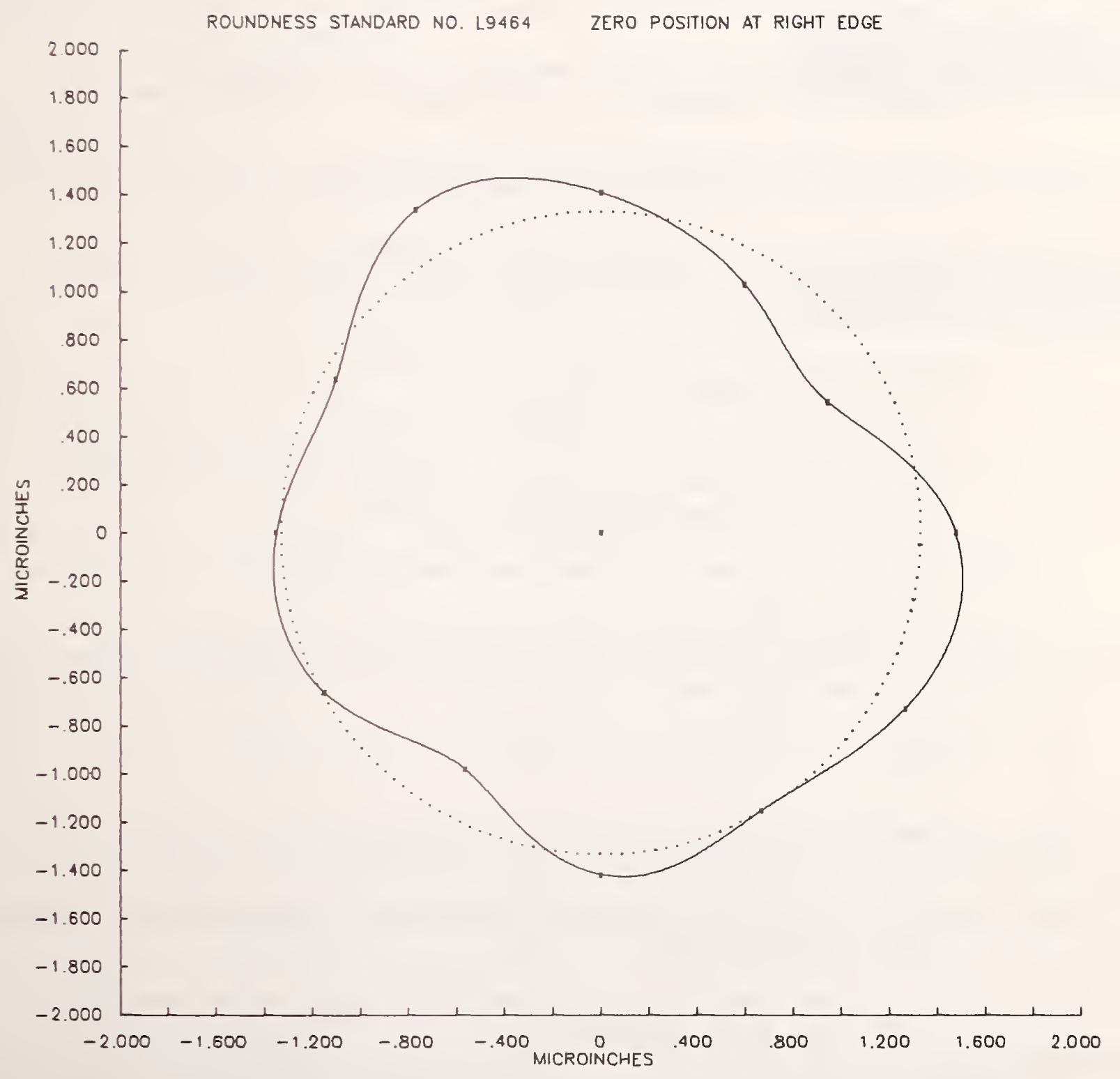

Figure 7.3 
References

[1] Ahlberg, J. H., Nilson, E. N., and Walsh, J. L., The Theory of Splines and Their Applications, Academic Press, 1967, Section 2.1.

[2] British Standard 3730:1964, Methods for the Assessment of Departures from Roundness, British Standards Institute, 1964.

[3] Cameron, J. M., The Use of the Method of Least Squares in Calibration, NBSIR 74-587, September 1974.

[4] Donaldson, R. R., A Simple Method for Separating Spindle Error from Test Ball Roundness Error, UCRL-73805 Preprint, Lawrence Livermore Laboratory, Livermore, California, 1972.

[5] Farago, Francis T., Handbook of Dimensional Measurement, Industria1 Press Inc., New York, 1968.

[6] Good, Charles H. and Laakso, L. H., Frequently Ignored Sources of Error in Roundness Measurement, SP64-42, American Society of Tool and Manufacturing Engineers, 1964.

[7] Miller, L., Engineering Dimensional Metrology, Edward Arnold Ltd., London, 1962.

[8] Moore, Wayne R., Foundations of Mechanical Accuracy, The Moore Special Tool Company, 1970.

[9] Reason, R. E., The Talyrond Handbook, Taylor, Taylor \& Hobson, Ltd., 1954, Part III.

[10] Reason, R. E., 1966 Report on the Measurement of Roundness, The Rank Organization, Rank Taylor Hobson.

[11] Thomas, Geoffrey G., Engineering Metrology, Butterworth and Company Ltd., London, 1974.

[12] UNIVAC, MATH-PACK Programmers Reference, Sperry Rand Corporation, 1970, pp. 2-68 through 2-72. 


\begin{tabular}{|c|c|c|c|}
\hline $\begin{array}{l}\text { U.S. DEPT. OF COMM. } \\
\text { BIBLIOGRAPHIC DATA } \\
\text { SHEET }\end{array}$ & $\begin{array}{l}\text { 1. PUBLICATION OR REPORT NO. } \\
\text { NBSIR. } 79-1758\end{array}$ & 2. Govt Aecestisn My & 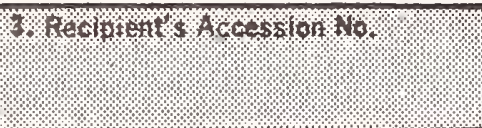 \\
\hline \multirow{2}{*}{\multicolumn{3}{|c|}{$\begin{array}{l}\text { 4. TITLE AND SUBTITLE } \\
\text { The Calibration of a Roundness Standard }\end{array}$}} & $\begin{array}{l}\text { 5. Publication Date } \\
\text { June } 1979 \\
\end{array}$ \\
\hline & & & A Perfoming Organization Code \\
\hline \multicolumn{3}{|l|}{$\begin{array}{l}\text { 7. AUTHOR(S) } \\
\text { Charles P. Reeve }\end{array}$} & 8. Performing Organ. Report No. \\
\hline \multirow{2}{*}{\multicolumn{3}{|c|}{$\begin{array}{l}\text { NATIONAL BUREAU OF STANDARDS } \\
\text { DEPARTMENT OF COMMERCE } \\
\text { WASHINGTON, DC } 20234\end{array}$}} & 19. Project Taskifllork Unit No. \\
\hline & & & 11. Contract/Grant No. \\
\hline \multicolumn{3}{|c|}{$\begin{array}{l}\text { 12. SPONSORING ORGANIZATION NAME AND COMPLETE ADDRESS IS } \\
\text { (Same as NO. 9) }\end{array}$} & $\begin{array}{l}\text { 13. Type of Report \& Period Covered } \\
\text { Finat } \\
\text { 17. Sransering Arency Code }\end{array}$ \\
\hline
\end{tabular}

15. SUPPLEMENTARY NOTES

Document describes a computer program; SF-185, FIPS Software Summary, is attached.

16. ABSTRACT (A 200-word or less factual summary of most sigrificant information. If document includes a significant bibliography or literature survey, mention it here.)

For the past decade the National Bureau of Standards has been making high precision roundness measurements using an algorithm which allows the spindle out-of-roundness to be separated from the true profile of the workpiece. The algorithm requires multiple traces on a roundness measuring instrument, and the resulting redundancy provides an estimate of the measurement precision. The primary purpose of this paper us to describe in detail the mathematical model used for this measurement process. Some related topics are discussed briefly and an example is given.

17. KEY WORDS (six to twelve entries; alphabetical order; capitalize only the first letter of the first key word unless a proper name; separated by semicolons)

Least squares circle; least squares estimation; polar graph; restraints; roundness standard; spindle error; standard deviation; stylus.

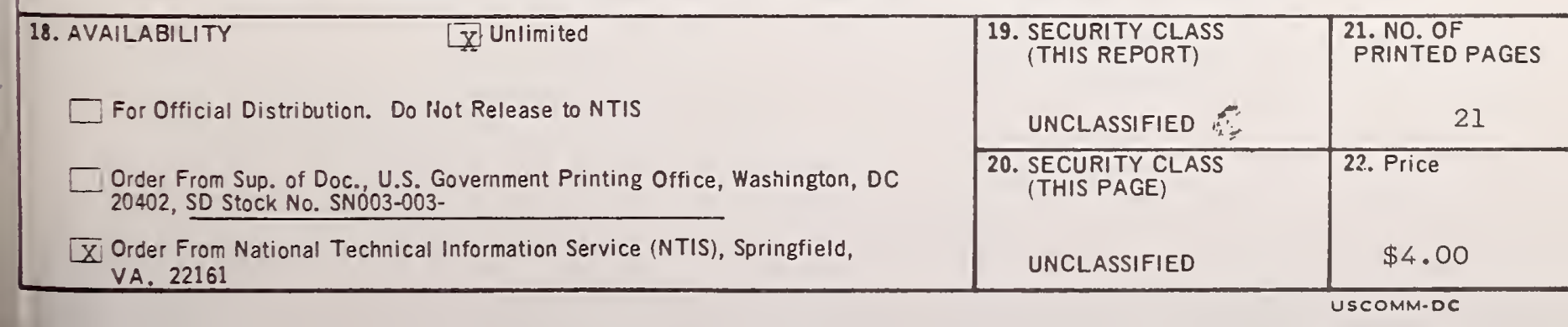




